\title{
Competitive interaction with keystone taxa induced negative priming under biochar amendments
}

\author{
Lijun Chen ${ }^{1,6+}$, Yuji Jiang ${ }^{1 *+} \mathbb{B}$, Chao Liang ${ }^{2}$, Yu Luo ${ }^{3}$, Qinsong Xu' ${ }^{4}$, Cheng Han $^{5}$, Qiguo Zhao ${ }^{1}$ and Bo Sun ${ }^{*}$
}

\begin{abstract}
Background: Biochar amendments have been widely proposed as a conventional and efficient strategy to promote soil organic carbon (SOC) sequestration via negative priming. Unfortunately, the extent and biological mechanisms responsible for biochar-induced negative priming are still not fully understood. Despite traditional explanations focused on the environmental filtering mechanisms of biochar amendments on microbial biomass and community composition underlying the priming effect on SOC dynamics, whether and how a biochar-induced competitive interaction with keystone taxa determines $\mathrm{SOC}$ mineralization in natural ecosystems has been minimally explored.

Results: Here, we paid particular attention to the relationships between the diversity and network structure of soil bacterial and fungal communities and SOC mineralization. A 3-year field experiment was conducted comprising five treatments: no fertilization, conventional fertilization, and conventional fertilization with three rates of biochar amendments. Biochar amendments considerably increased soil moisture capacity and $\mathrm{pH}$ and subsequently shaped the composition and co-occurrence networks of soil bacterial and fungal communities. Importantly, network analysis revealed that the biochar amendments triggered the competitive interaction with putative keystone taxa in the bacterial and fungal networks. Structural equation modeling suggested that the competitive interaction with keystone taxa promoted bacterial and fungal diversity and consequently reduced carbohydrate catabolism and soil metabolic quotient. Stable isotope probing incubations further provided consistent evidence of competition by keystone taxa with the increases in bacterial and fungal diversity under the biochar amendments.
\end{abstract}

Conclusions: We found that biochar-induced competition with keystone taxa stimulated the bacterial and fungal diversity and consequently decreased SOC mineralization. The comprehensive understanding of the unexplored biological mechanisms underlying the biochar-induced negative priming may provide crucial implications for enabling SOC sequestration.

Keywords: Biochar, Bacterial and fungal diversity, Competitive interaction, DNA-SIP microcosms, Keystone taxa, Soil organic carbon mineralization

\section{Background}

Soil organic carbon $(\mathrm{SOC})$ sequestration is of fundamental importance in agricultural soils, because it mitigates atmospheric carbon dioxide $\left(\mathrm{CO}_{2}\right)$ emissions and enhances soil fertility [1]. In this context, biochar application has been confirmed as an efficient way to mediate SOC

\footnotetext{
* Correspondence: yjjiang@issas.ac.cn; bsun@issas.ac.cn

${ }^{\dagger}$ Lijun Chen and Yuji Jiang contributed equally to this work.

${ }^{1}$ State Key Laboratory of Soil and Sustainable Agriculture, Institute of Soil Science, Chinese Academy of Sciences, No. 71 East Beijing Road, Nanjing 210008, China

Full list of author information is available at the end of the article
}

sequestration in agricultural soils [2]. Biochar has the potential to regulate native SOC mineralization via positive, neutral, or negative priming effects [3]. These uncertainties in SOC mineralization induced by the biochar amendments could be attributed to the remarkable shifts in microbial abundance and composition [4-6]. Bulk of traditional explanatory studies have demonstrated that soil physicochemical conditions altered by the biochar amendments, especially $\mathrm{pH}$ and hydrologic characteristics, play a crucial role in controlling the biomass and composition of soil microbial communities [2]. Biochar imprints the alterations in the composition of soil microbial communities

(c) The Author(s). 2019 Open Access This article is distributed under the terms of the Creative Commons Attribution 4.0 International License (http://creativecommons.org/licenses/by/4.0/), which permits unrestricted use, distribution, and 
that emerge from the significantly increased ratios of fungi to bacteria and Gram-positive bacteria to Gram-negative bacteria [7, 8]. Soil microbial communities fuel SOC storage directly through their catabolic decomposition and anabolic synthesis and facilitate negative priming in terrestrial ecosystems $[9,10]$. Alternatively, negative priming may occur owing to the decreased turnover rate of the existing SOC by suppressing microbial activity [11]. Until now, the essential questions about the biological mechanisms of biochar-induced negative priming by microbial communities are still far from being adequately addressed.

Network-based analytical approach is a powerful tool to infer the microbial interactions and keystone taxa of the complex networks in natural environments [12]. Microbial keystone taxa are highly connected taxa that individually or in a guild show great explanatory power of network structure and functioning irrespective of their abundance [13]. The taxa interactions and keystone taxa in the networks are often pertinent to the major shifts in the whole community structure [14]. It is reasonable to suppose, therefore, that biochar exerts important influences on the microbial interactions and keystone taxa of the bacterial and fungal co-occurrence networks [15]. Biochar has been reported to substantially improve microbial diversity, suggesting the enhanced growth of a few novel bacterial groups with previously low relative abundance [16]. In particular, the new emerging keystone taxa were highly connected in the microbiome networks, which contribute largely to modulating microbial diversity and community structure and explain microbiome compositional turnover better than whole individuals combined [14]. Accumulating theoretical and empirical evidence suggests the importance of competition in stimulating taxa co-existence and diversity through evolutionary processes [17, 18]. Hitherto, few reports have yet highlighted the mechanisms of competitive interaction accompanied by keystone taxa responsible for microbial diversity. Specifically, there is a need for further experimental evidence to verify the competitive interaction with keystone taxa in the microbial networks.

To predict SOC dynamics, it is critical to understand how the bacterial and fungal communities change in terms of their richness and diversity under the biochar amendments. So far, scarce attention has been paid to the roles of microbial diversity in mediating SOC dynamics. Despite understanding that the impact of microbial richness on community functioning depends ultimately on the traits of keystone taxa in a microbiome [19], there is a little prediction of how competitive interaction mediates the diversity-functioning relationships. The direction and extent to which microbial interactions affect diversity-functioning relationships are still a matter of considerable controversy. Intense competitive interactions with keystone taxa can attenuate or reverse diversity-functioning relationships [20]. The omission of microbial interactions from biochar-induced negative priming posits a key uncertainty for projecting the magnitude of SOC sequestration.

Based on the literature cited above, we aimed to gain a mechanistic understanding of how biochar-induced competitive interaction with keystone taxa determined SOC mineralization. Specifically, the present study was structured to clarify three questions: (1) Do the biochar amendments affect the biomass, composition, and cooccurrence networks of soil bacterial and fungal communities? (2) Does the competitive interaction with keystone taxa exhibit a substantial impact on soil bacterial and fungal diversity under the biochar amendments? If so, then (3) what is the biological mechanism responsible for biochar-mediating SOC mineralization via priming effects? To achieve these goals, we conducted a 3-year field experiment under three rates of biochar amendments along with two non-biochar amendments. We observed that the competitive interaction with keystone taxa in the networks promoted bacterial and fungal diversity and then decreased soil mineralization. Our work describes new entry points for the undefined biological mechanisms of biochar-induced negative priming effect on SOC mineralization.

\section{Results}

Soil physicochemical properties and SOC mineralization

Biochar amendments significantly affected soil physicochemical conditions $\left(F_{(4,11)}=2.67-73.56, P<0.05\right)$. Soil $\mathrm{pH}, \mathrm{SOC}$, total nitrogen, total phosphorus, available potassium, and available phosphorus were significantly elevated by the medium and high biochar ( $\mathrm{MB}$ and $\mathrm{HB}$ ) amendments relative to conventional fertilization (CF) (Additional file 1: Table S1, $P<0.05$ ). Similarly, total potassium ranged from 20.74 to $23.55 \mathrm{~g} \mathrm{~kg}^{-1}$, with a significant increase under the HB amendment $(P<0.05)$. However, bulk density and available nitrogen under the $\mathrm{MB}$ and $\mathrm{HB}$ amendments were significantly lower than those under the CF treatment (Additional file 1: Table S1, $P<0.05)$. In comparison, there were no significant effects of biochar obtained for cation exchange capacity $(P=0.982)$. Soil moisture capacity $(\mathrm{SMC})$ under the three biochar amendments increased sharply when soil water suction was higher than $0.03 \mathrm{MPa}$ (Additional file 1: Figure S1, $P<0.05)$. The diameter $-\theta$ curves showed that the biochar amendments increased the size of soil effective pores to larger than $0.1 \mu \mathrm{m}$ (Additional file 1: Figure S1). The results of soil water characteristic curve indicated that the water retention capacity gradually increased with the increasing rates of biochar amendments. SOC mineralization was estimated by both soil metabolic quotient $\left(q \mathrm{CO}_{2}\right)$ and microbial carbon metabolism 
represented by average well color development (AWCD). On average, the values of AWCD and $q \mathrm{CO}_{2}$ significantly decreased by $36.8 \%$ and $16.3 \%$ under the biochar amendments compared to the CF treatment, respectively (Fig. 1, $P<0.05$ ), and the $\mathrm{MB}$ amendment was characterized by the lowest value of $\mathrm{AWCD}$ and $q \mathrm{CO}_{2}$. Carbohydrate utilization followed a similar trend to the AWCD value of whole plate (Fig. 1, $P<0.05$ ). However, no significant differences were observed in the utilization of other five carbon sources, including carboxylic acid, amino acids, phenolic acid, amines, or polymers.

The biomass, diversity, and composition of soil bacterial and fungal communities

Soil samples were subjected to phospholipid fatty acid (PLFA) analysis for determining microbial biomass. Microbial biomass measured as total PLFA was significantly higher under the $\mathrm{MB}$ and $\mathrm{HB}$ amendments than under the $\mathrm{CF}$ treatment (Additional file 1: Figure S2, $P<0.05)$. Similar to total PLFA, the biomass of microbial-specific groups significantly increased under the $\mathrm{MB}$ and $\mathrm{HB}$ treatments in terms of bacteria (21.3\% and $34.2 \%)$, Gram-negative bacteria $(29.1 \%$ and 47.5\%), Gram-positive bacteria (9.1\% and $15.1 \%)$, actinomycetes (13.8\% and $17.8 \%)$, and fungi $(14.2 \%$ and $31.8 \%$ ) (Additional file 1: Figure S2, $P<0.05$ ).

The diversity and compositions of soil bacterial and fungal communities were detected by Illumina sequencing of $16 \mathrm{~S} r R N A$ and ITS gene amplicons. After rarefaction to equal sequencing depth, we obtained a total of 409,125 and 446,565 high-quality bacterial and fungal sequences with an average of 1652 bacterial and 298 fungal OTUs across all samples. The $\mathrm{MB}$ and $\mathrm{HB}$ amendments significantly increased bacterial and fungal diversity estimated by the Shannon index and Chaol richness compared with the no fertilizer $(\mathrm{CK})$ and $\mathrm{CF}$ treatments (Fig. 2). The bacterial communities consisted mainly of Actinobacteria (31.2\%), Alphaproteobacteria (20.4\%), Chloroflexi (8.73\%), Acidobacteria (7.2\%), Betaproteobacteria (6.3\%), Bacteroidetes (5.4\%), Gammaproteobacteria
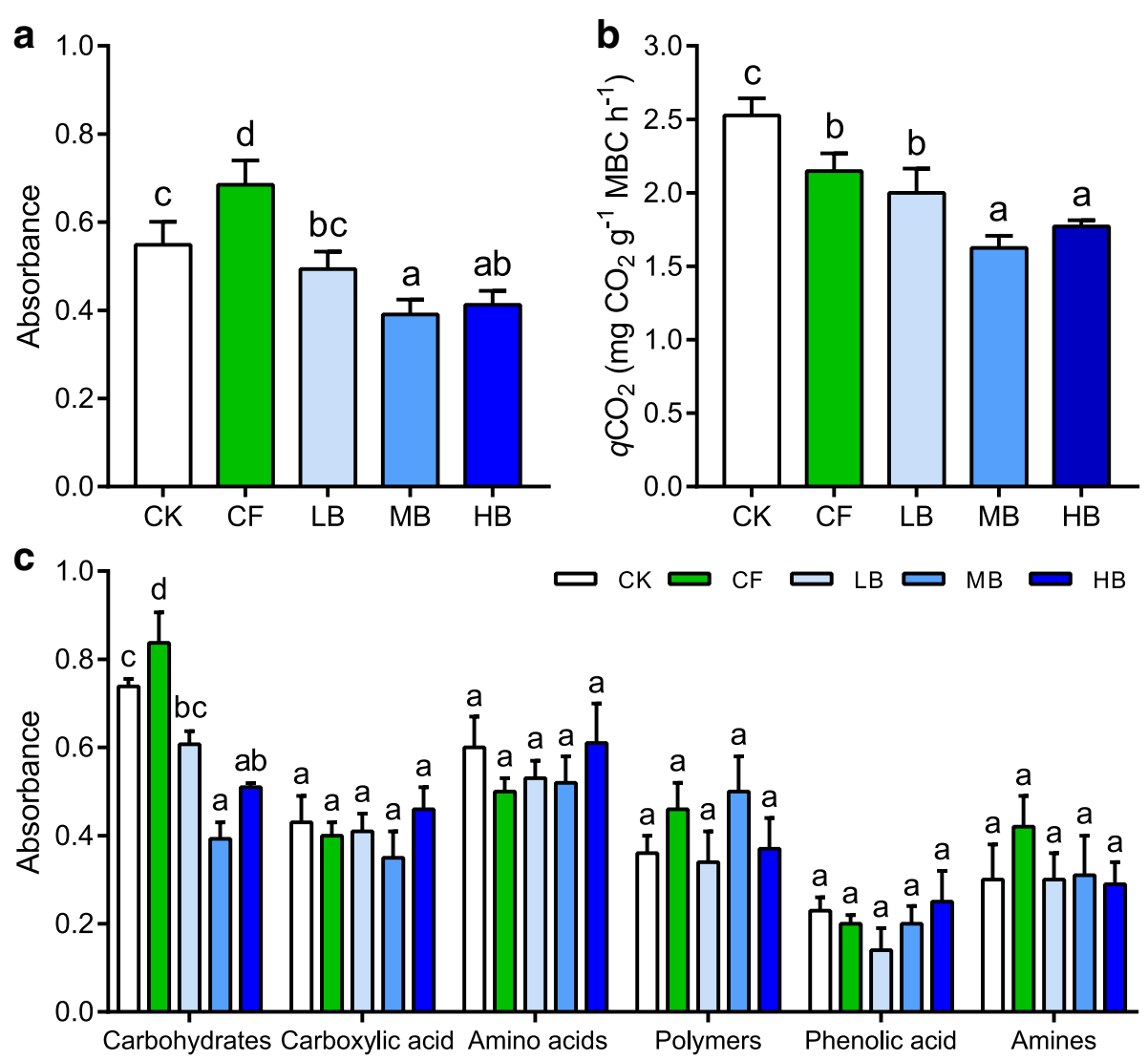

Fig. 1 Effects of biochar amendments on microbial carbon metabolic activities (a) and soil metabolic quotient (b; $\left.q \mathrm{CO}_{2}\right)$ in the flied experiment. Carbon source utilization rates based on six specific carbon families are analyzed by the Biolog EcoPlates including carbohydrates, carboxylic acids, amino acids, polymers, phenolic acid, and amines/amides (c). Microbial carbon metabolism is reflected by the average well color development (AWCD). Bars with different lowercase letters indicate statistical significant differences $(P<0.05)$ as revealed by Bonferroni's post hoc tests. CK, no fertilizer; CF, conventional fertilization; LB, low biochar with $2400 \mathrm{~kg} \mathrm{ha}^{-1}$ year $^{-1}$; MB, medium biochar with $7200 \mathrm{~kg} \mathrm{ha}^{-1}$ year ${ }^{-1}$; HB, high biochar with $12,000 \mathrm{~kg} \mathrm{ha}^{-1}$ year $^{-1}$ 

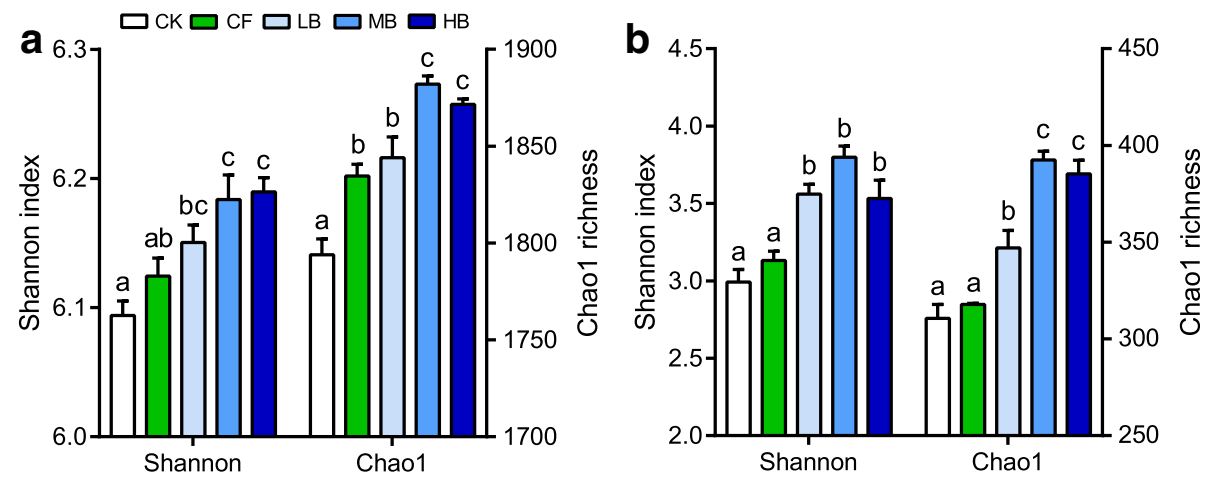

Fig. 2 Biochar amendments alter the bacterial (a) and fungal (b) diversity in the field experiment. Calculation of the Shannon index and Chao1 richness is based on OTU tables rarified to the same sequencing depth. Bars with different lowercase letters are significantly different $(P<0.05)$ by Bonferroni's post hoc tests. CK, no fertilizer; CF, conventional fertilization; LB, low biochar with $2400 \mathrm{~kg} \mathrm{ha}^{-1}$ year $^{-1}$; MB, medium biochar with $7200 \mathrm{~kg} \mathrm{ha}^{-1}$ year $^{-1} ; \mathrm{HB}$, high biochar with $12,000 \mathrm{~kg} \mathrm{ha}^{-1}$ year $^{-1}$

(5.0\%), Gemmatimonadetes (4.6\%), and Firmicutes (3.5\%) (Additional file 1: Figure S3). The principal coordinate analysis of Bray-Curtis distances displayed that the bacterial community compositions under the biochar amendments were significantly $(P<0.01)$ clustered together on the basis of their taxonomy (Additional file 1: Figure S4). When considering the relative bacterial abundances, Actinobacteria, Gammaproteobacteria, and Gemmatimonadetes were enriched under the biochar amendments, while Alphaproteobacteria and Acidobacteria were overrepresented under the $\mathrm{CK}$ and $\mathrm{CF}$ treatments $(P<0.05)$. The fungal community compositions were dominated by Ascomycota (89.3\%) belonging to the classes Sordariomycetes (60.8\%), Eurotiomycetes (23.0\%), and Dothideomycetes (3.2\%), followed by the rare phyla Basidiomycota (8.1\%) and Zygomycota (2.0\%) (Additional file 1: Figure S3). Similar to the bacterial community, the comparison of the fungal community compositions by principal coordinates analysis revealed a significant $(P<0.01)$ separation among the biochar amendments and two compartments (CK and CF) (Additional file 1: Figure S4). At the phylum/class level, the taxonomical differences resulted primarily from the higher abundance of Basidiomycota but the lower abundance of Sordariomycetes $(P<0.05)$. Overall, the similarities of soil bacterial and fungal community composition within the biochar amendments were significantly $(P<0.05)$ higher than those between the biochar amendments and their counterparts including $\mathrm{CK}$ and $\mathrm{CF}$ (Additional file 1: Figure S4).

\section{Bacterial and fungal co-occurrence networks}

To identify the co-occurrence patterns of soil bacterial and fungal communities and niche partition in the non-amended (CK and $\mathrm{CF}$ ) and biochar-amended (LB, $\mathrm{MB}$, and $\mathrm{HB}$ ) treatments, we next constructed the bacterial and fungal networks in which nodes and links were calculated by the robustness of the co-occurrence scores. Although there were more positive correlations in the bacterial and fungal networks regardless of treatments, the ratios of negative correlations to positive correlations were increased under the biochar amendments (Fig. 3, Additional file 1: Table S2). Multiple topological properties of the bacterial and fungal co-occurrence patterns pronouncedly varied in the biochar-amended networks in terms of the numbers of nodes and edges, average connectivity, and average clustering coefficient (Additional file 1: Table S2).

The bacterial and fungal networks were clustered into modules that could be examined to find significant module-trait relationships. Our results indicated that both bacterial and fungal networks could be decomposed into smaller coherent modules and that their eigengenes were strongly correlated with $\mathrm{SMC}$ and $\mathrm{pH}$ (Figs. 3, 4 and 5). The bacterial modules I and $\mathrm{V}$ and fungal modules II and IV were positively correlated with carbohydrate utilization and $q \mathrm{CO}_{2}$ in the non-amended networks (Fig. 5). However, the bacterial modules I and II and fungal module II showed negative correlations with carbohydrate catabolism and $q \mathrm{CO}_{2}$ in the biocharamended networks. Noteworthy, the bacterial modules I and II and fungal module II were positively associated with bacterial and fungal diversity, respectively (Fig. 5). Furthermore, the individual nodes displayed discrepant roles in the microbial networks according to the withinmodule connectivity $Z$ and among-module connectivity $P$. For the non-amended network, the bacterial genus Sphingomonas (Alphaproteobacteria) and the fungal genus Aspergillus (Eurotiomycetes) were detected as the module hubs. Intriguingly, the statistically identified keystone taxa displayed positive relationships with connected members in their own module, as well as with carbohydrate catabolism and $q \mathrm{CO}_{2}$ (Figs. 3 and 4, Table 1). For 


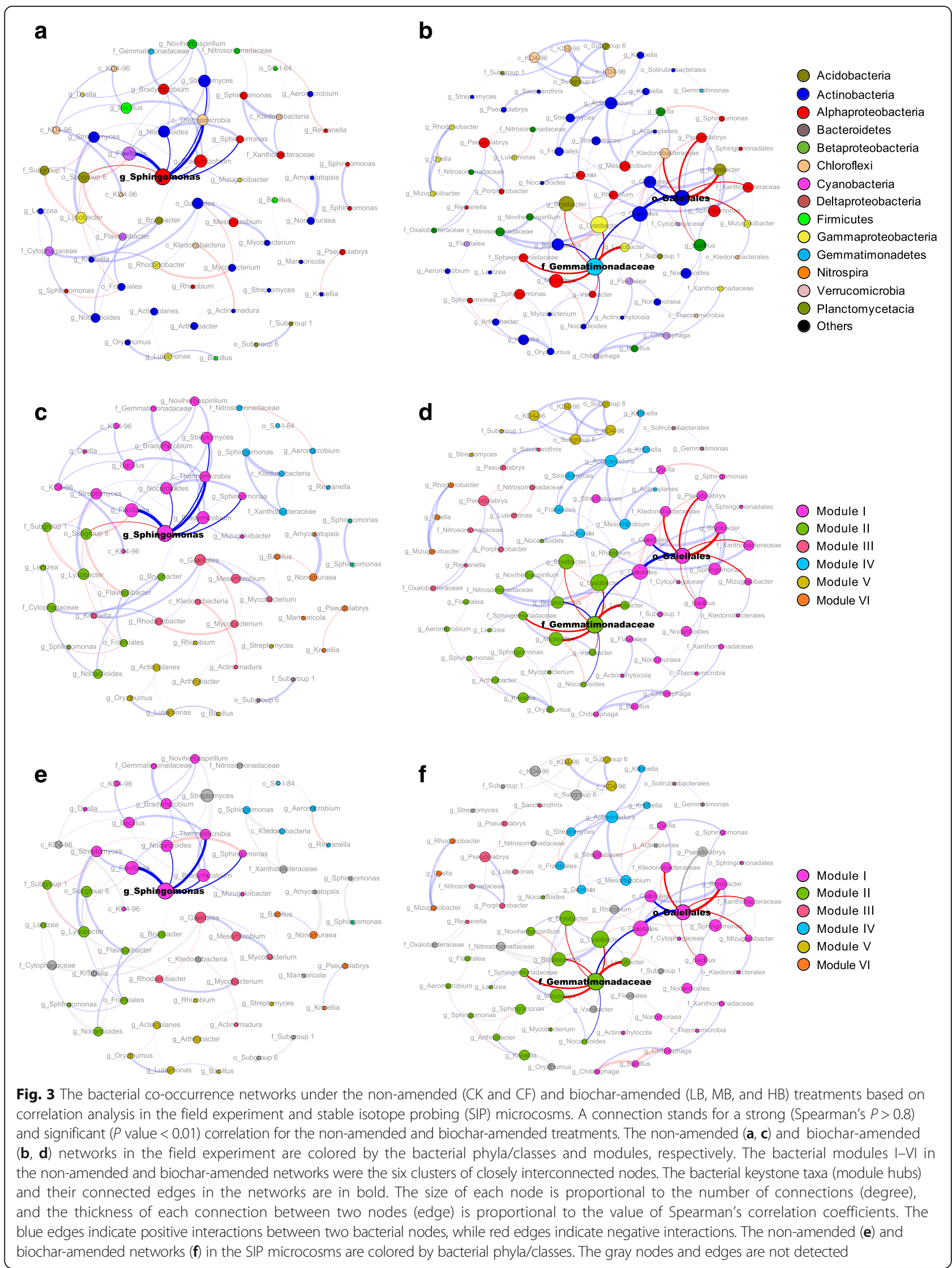



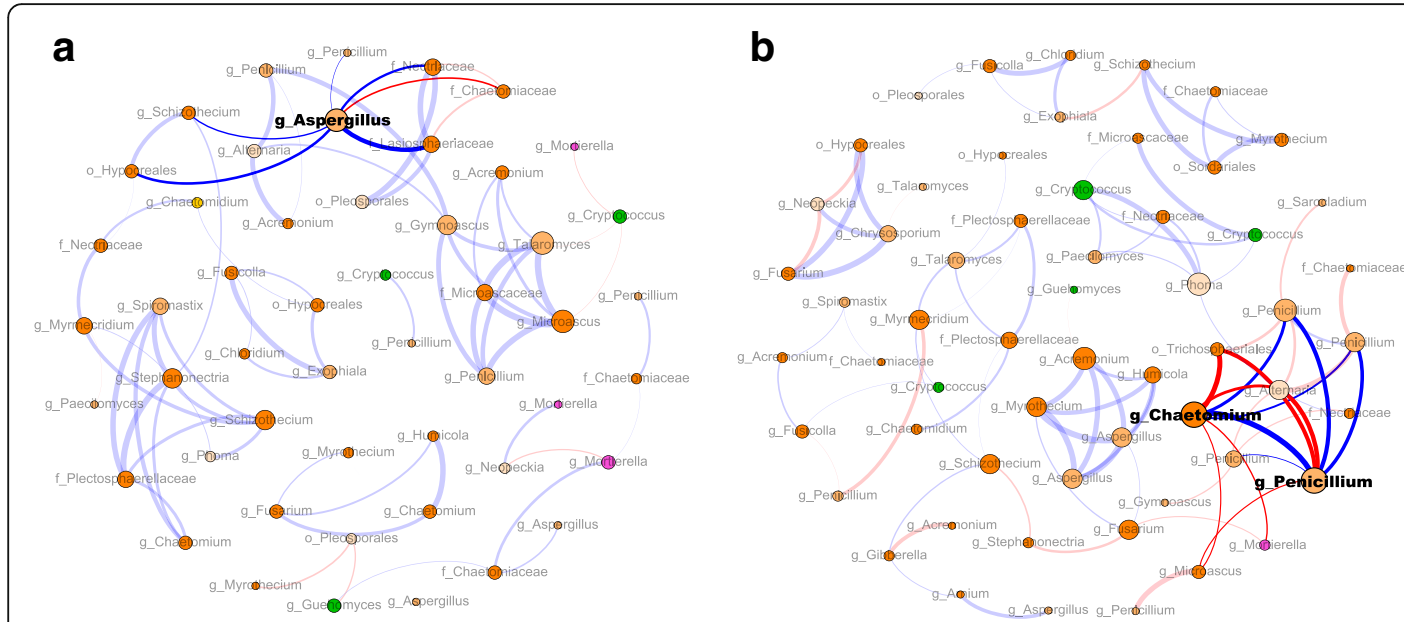

Dothideomycetes

Eurotiomycetes

Sordariomycetes

Basidiomycota

Zygomycota

Others
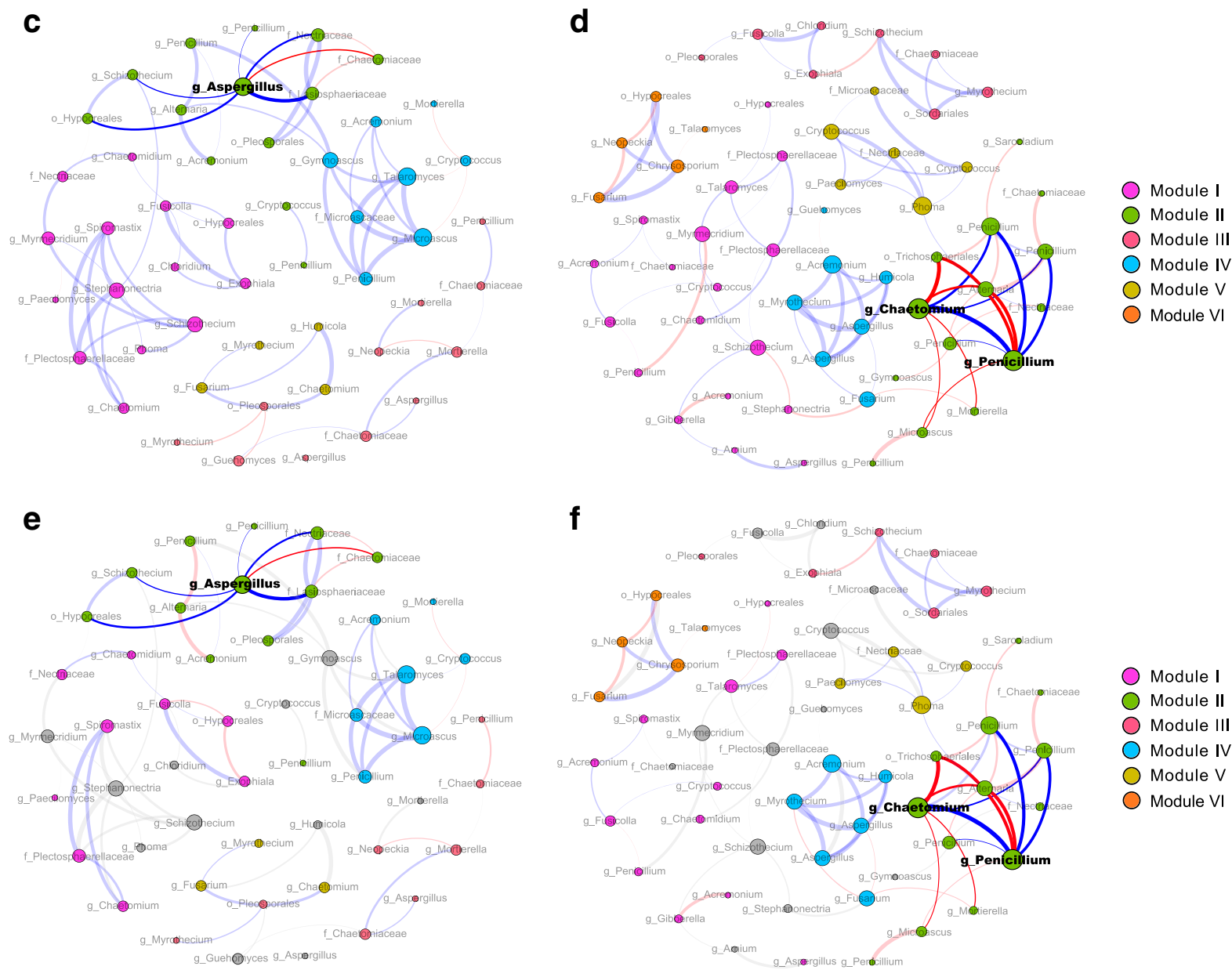

Fig. 4 The fungal co-occurrence networks under the non-amended (CK and $C F$ ) and biochar-amended ( $L B, M B$, and HB) treatments based on correlation analysis in the field experiment and stable isotope probing (SIP) microcosms. A connection stands for a strong (Spearman's $P>0.8$ ) and significant $(P$ value $<0.01)$ correlation for the non-amended and biochar-amended treatments. The non-amended $(\mathbf{a}, \mathbf{c})$ and biochar-amended $(\mathbf{b}, \mathbf{d})$ networks in the field experiment are colored by the fungal phyla/classes and modules, respectively. The fungal modules I-VI in the non-amended and biochar-amended networks were the six clusters of closely interconnected nodes. The fungal keystone taxa (module hubs) and their connected edges in the networks are in bold. The size of each node is proportional to the number of connections (degree), and the thickness of each connection between two nodes (edge) is proportional to the value of Spearman's correlation coefficients. The blue edges indicate positive interactions between two fungal nodes, while red edges indicate negative interactions. The non-amended (e) and biochar-amended networks ( $\mathbf{f}$ ) in the SIP microcosms are colored by fungal phyla/classes. The gray nodes and edges are not detected 


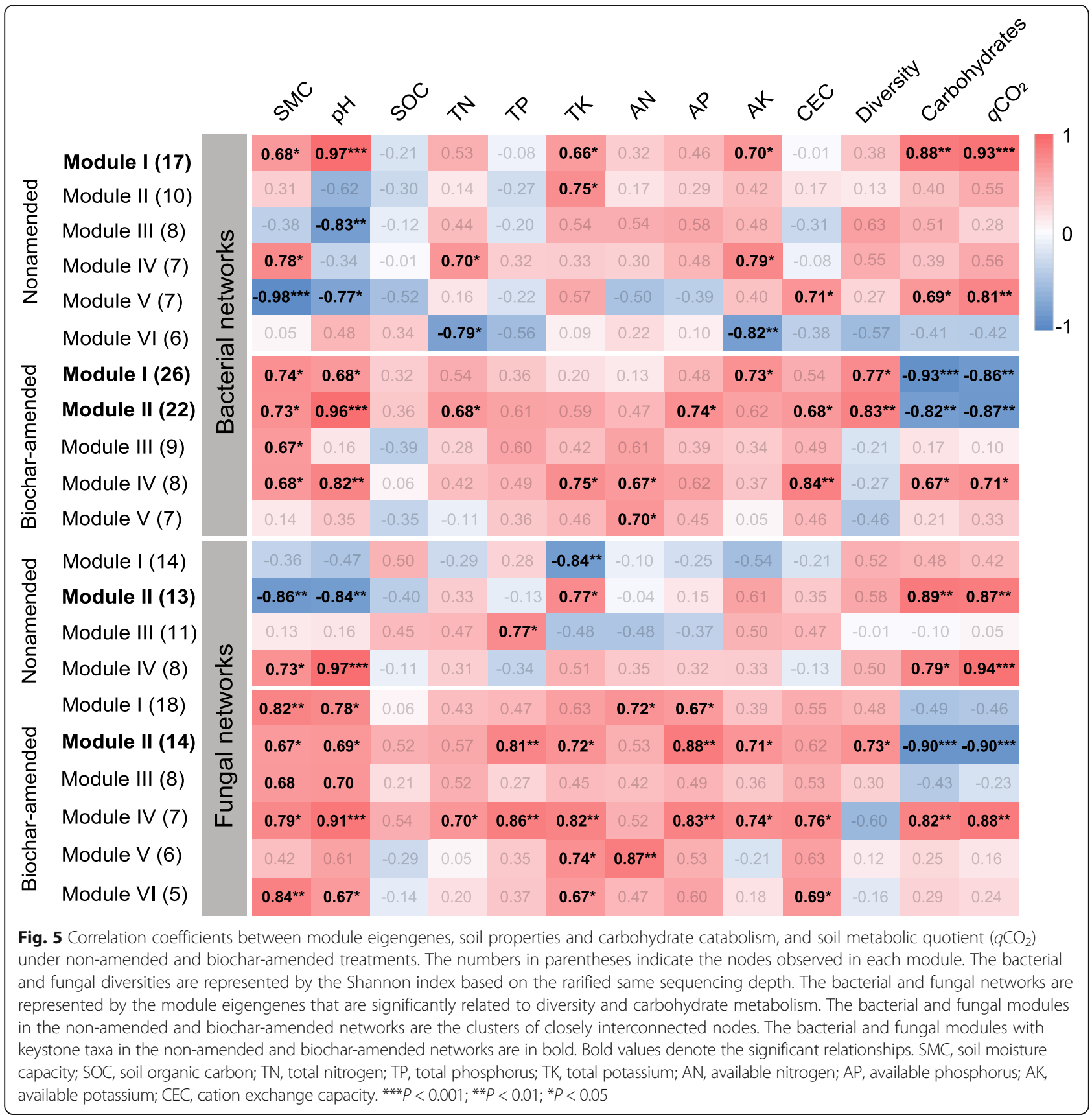

the biochar-amended network, the bacterial genera Arthrobacter (Actinobacteria) and Gemmatimonadaceae (Gemmatimonadetes) and fungal genera Chaetomium (Sordariomycetes) and Penicillium (Eurotiomycetes) were analogously designated as module hubs. However, these keystone taxa were of intensely negative relevance for the linked nodes in the individual modules and for carbohydrate catabolism and $q \mathrm{CO}_{2}$ (Figs. 3 and 4, Table 1). Collectively, the results suggested that these particular nodes were mandatory to summarize a module related to carbohydrate catabolism and $q \mathrm{CO}_{2}$.
Soil properties and microbial community affected SOC dynamics

The diversity and richness of soil bacterial and fungal communities were positively correlated with SMC and $\mathrm{pH}(r=0.732 \sim 0.937, P<0.01)$, but were negatively related to carbohydrate utilization and $q \mathrm{CO}_{2} \quad(r=-0.927$ to $-0.720, P<0.01$ ) (Additional file 1: Table S3). However, the bacterial and fungal biomasses showed no significant correlations with carbohydrate catabolism and $q \mathrm{CO}_{2}$ $(r=-0.490$ to $-0.271, P>0.05)$. Random forest modeling was used to evaluate the potential important predictors of 


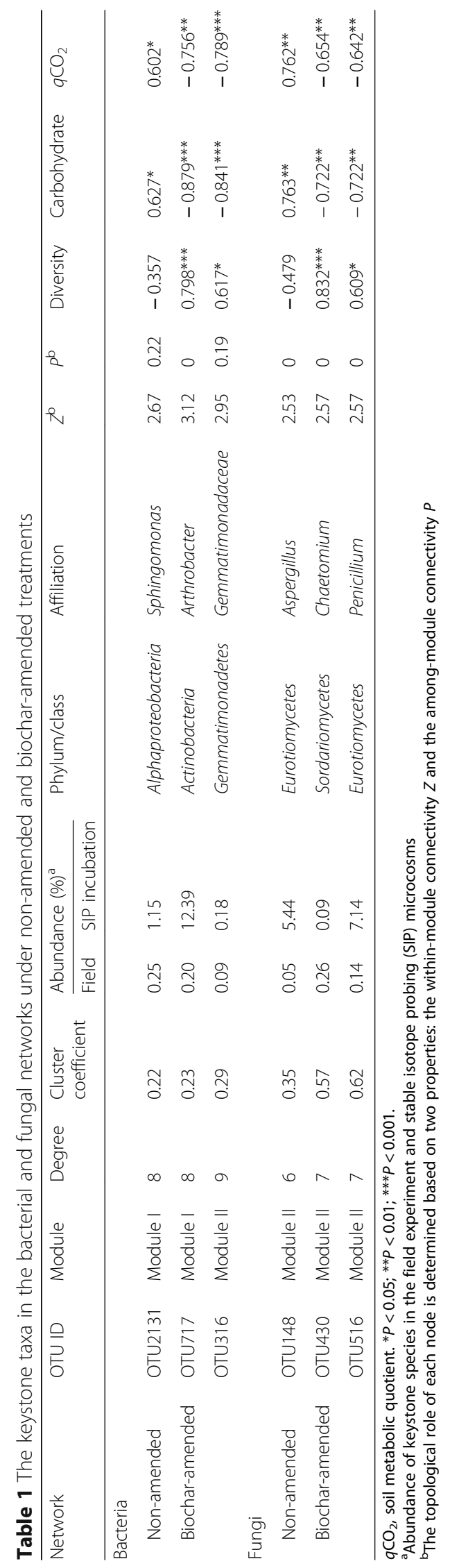


carbohydrate catabolism and $q \mathrm{CO}_{2}$. Overall, we found that $\mathrm{SMC}$ and $\mathrm{pH}$ were the two main determinants of soil properties for carbohydrate utilization and $q \mathrm{CO}_{2}$ (Additional file 1: Figure S5). The mean square error increased $13.6 \%$ and $15.7 \%$ for carbohydrate utilization and $q \mathrm{CO}_{2}$, respectively, when removing the predictor of SMC, and increased $10.9 \%$ and $13.3 \%$, respectively, when removing the predictor of soil $\mathrm{pH}$. The bacterial and fungal diversity (Shannon index) contributed more pronounced effects to carbohydrate utilization and $q \mathrm{CO}_{2}$ than the networks (module eigengenes) (Additional file 1: Figure S5). Structural equation modeling (SEM) was further used to evaluate the direct and indirect impacts of soil properties and soil bacterial and fungal communities on SOC mineralization under the non-amended and biochar-amended treatments. Soil bacterial and fungal networks (module eigengenes) were positively related to carbohydrate catabolism under the non-amended treatments (Fig. 6). We observed that SMC showed a directly negative influence on carbohydrate catabolism under the biochar-amended treatments. Importantly, the modules with keystone taxa may contribute more to soil bacterial and fungal networks than those without keystone taxa (Fig. 6). The bacterial and fungal diversities (Shannon index) were positively correlated with the networks (module eigengenes), but were negatively associated with carbohydrate catabolism under the biochar-amended treatments. SEM suggested that bacterial diversity exhibited a larger impact on carbohydrate catabolism than fungal diversity (Fig. 6).

\section{SIP incubations}

We conducted SIP experiments to trace the bacterial and fungal taxa capable of utilizing carbohydrates in the non-amended and biochar-amended networks. The targeted bacterial and fungal populations were successfully labeled during incubations with ${ }^{13} \mathrm{C}$-glucose. The bacterial and fungal communities were less diverse in the labeled libraries of ${ }^{13} \mathrm{C}$-incubated samples than in those of ${ }^{12} \mathrm{C}$-controls (Additional file 1: Figure S6), suggesting that only a portion of the bacterial and fungal groups using glucose compared to the overall microbial community. In fact, approximately half of all detected bacterial $(46.5 \%)$ and fungal $(54.7 \%)$ genera were involved in glucose utilization. Furthermore, the successful targeting of carbohydrate catabolic populations presented significantly higher diversity under the biochar-amended treatments than under the non-amended treatments (Additional file 1: Figure S6, $P<0.05$ ). For the bacterial community, the members of Actinobacteria (52.4\% and 19.6\%), Alphaproteobacteria (16.2\% and 32.5\%), Gammaproteobacteria (6.6\% and 9.2\%), and Betaproteobacteria (4.4\% and 6.6\%) were dominant in the labeled libraries of ${ }^{13} \mathrm{C}$-incubated samples and ${ }^{12} \mathrm{C}$-controls, respectively (Additional file 1: Figure S7). The fungal community consisted of Ascomycota, predominated by Sordariomycetes (70.0\% and $52.3 \%)$, Eurotiomycetes (23.1\% and $22.5 \%)$, and Dothideomycetes (1.6\% and 6.1\%) in the labeled libraries of ${ }^{13} \mathrm{C}$-incubated samples and ${ }^{12} \mathrm{C}$-controls, respectively (Additional file 1: Figure S7). On average, the abundance of bacterial phylum Actinobacteria and fungal phylum Sordariomycetes in the ${ }^{13} \mathrm{C}$-glucose-utilizing
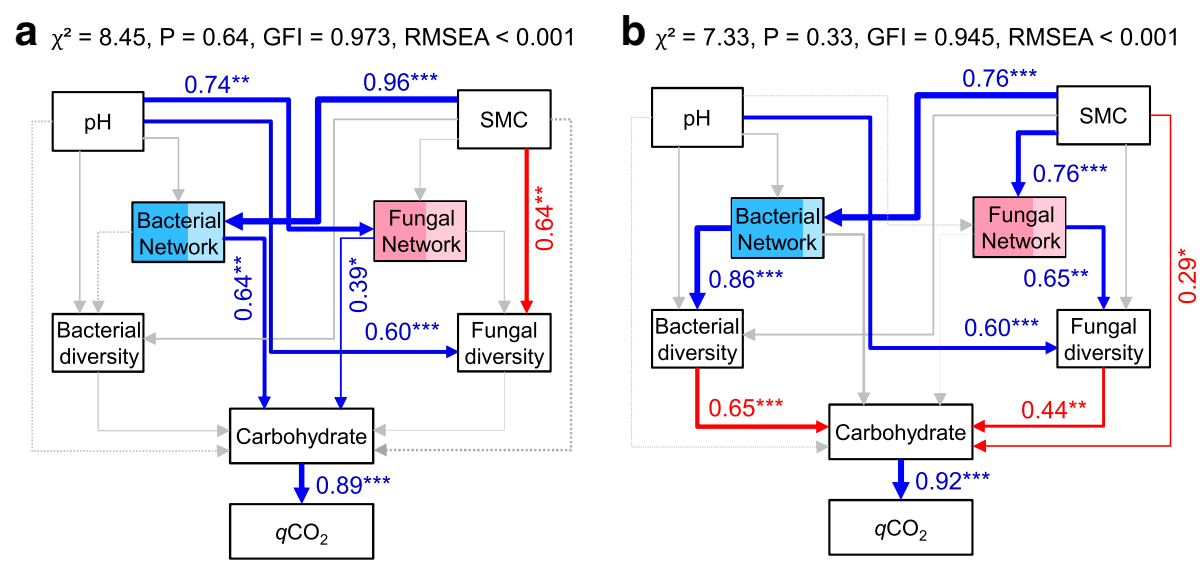

Fig. 6 The impacts of soil properties and bacterial and fungal community on carbohydrate metabolism and soil metabolic quotient $\left(q\left(\mathrm{CO}_{2}\right)\right.$ as estimated using the structural equation modeling under the non-amended (a) and biochar-amended (b) treatments. Blue lines indicate positive relationships, while red lines indicate negative relationships. The bacterial and fungal diversities are represented by the Shannon indexes based on the rarified same sequencing depth, and the bacterial and fungal networks are represented by the module eigengenes that are significantly related to diversity and carbohydrate metabolism. The contributions of the module with or without keystone taxa in the bacterial (blue rectangle) and fungal networks (red rectangle) were colored by dark or light, respectively. The width of arrows indicates the strength of significant standardized path coefficients $(P<0.05)$. Paths with non-significant coefficients are presented as gray lines. SMC, soil moisture capacity. ${ }^{* *} P<0.001 ;{ }^{*} P<0.01 ;{ }^{*} P<0.05$ 
populations increased 1.6 and 1.2 times in the biocharamended treatments compared to the non-amended treatments, respectively. A vast majority of the total nodes were identified as potential glucose-utilizing bacteria $(80 \%$ and $84 \%$ ) and fungi (76\% and $79 \%$ ) in the biochar non-amended and amended networks, respectively (Figs. 3 and 4, Additional file 1: Table S2). All bacterial and fungal keystone taxa in the non-amended and biochar-amended networks were detected among these potential ${ }^{13} \mathrm{C}$-glucose-utilizing populations. The bacterial and fungal module hubs in the non-amended networks exhibited positive correlations with the connected nodes in their individual modules, while those in the biochar-amended networks were negatively associated with their linked nodes (Figs. 3 and 4).

\section{Discussion}

\section{Biochar amendments altered the bacterial and fungal communities}

Biochar amendments as a widely proposed strategy to adjust SOC storage and improve soil fertility are a topic of growing interest and strong concern. In the shortterm field experiment, we chose three rates of biochar amendments to assess the biochar effects on soil characteristics. Our results clearly revealed that biochar amendments significantly reduced bulk density, but increased soil $\mathrm{pH}$, water holding capacity, and easily available substrates. Biochar amendments are expected to immediately increase the $\mathrm{pH}$ of adjacent soil due to the alkaline $\mathrm{pH}$ of biochar, which relies heavily on the nature of feedstock materials and pyrolysis temperature. Biochar made from crop residues and formed at relatively high temperature tends to have high ash contents and carbonates [21]. Biochar is found to simultaneously promote SMC and available water to microorganisms, which can be attributed mainly to the reduced bulk density and increased proportion of large voids and porosity [22]. In addition, biochar characteristics of surface charge can facilitate the transfer of water and nutrients from bulk soil into pore structure. Due to the high internal surface area and porosity, biochar enhances water holding capacity and effectively retains moist pore spaces for continued hydration of microbial populations as soils dry [23].

The increased $\mathrm{pH}$ and $\mathrm{SMC}$ under the $\mathrm{MB}$ and $\mathrm{HB}$ amendments may enhance microbial spore germination, colonization, and reproduction rates and consequently increase bacterial and fungal biomass. Given that biochar induced the changes in microbial biomass, it was extremely unlikely that such changes in abundance were spread equally across different functional groups. Changes in physicochemical properties and substrate utilization under the biochar amendments would differentially tailor the composition and network of soil bacterial and fungal communities. The PCoA combined with network analysis confirmed that the compositions and network structures of the bacterial and fungal communities in the biocharamended soils were significantly different from those in the non-amended soils (Figs. 3 and 4, Additional file 1: Figure S4 and Table S2). Biochar amendments directly triggered the changes in the bacterial and fungal community structures by promoting the abundance of Grampositive bacteria and saprotrophic fungi. These results suggested that differential responses of fungal and bacterial taxa to the preferred energy sources for their metabolic needs caused some microbial groups to become competitively dominant. Select Gram-positive bacteria preferentially thrive on the surface of fresh biochar and often excrete highly complex sets of lignin-degrading oxidative enzymes necessary to depolymerize the highly complex biochar-derived C [11, 24]. Additionally, saprotrophic fungi have exceptional enzymatic capabilities to degrade biochar via the production of peroxidase, phenoloxidase, and laccase [25]. In contrast to Gram-positive bacteria, saprotrophic fungi occupy a hyphal, invasive growth habit, which gives them access to effectively colonize the interior of biochar particles.

The major changes in topological and modular features of the bacterial and fungal networks were mirrored by the alterations in community composition. The coupling linkages of the bacterial and fungal networks increased in the negative direction under the biochar amendments, suggesting antagonistic or competitive interactions for substrate acquisition. The biochar-amended networks with a higher average connectivity displayed the more complex coupling among microbes. The module in the network suggested that the microbial populations within it had similar ecological niches and functional interdependences [26]. Soil pH and SMC have been interpreted as the primary predictors of topological network properties involving network complexity and modularity [15, 27]. The increased $\mathrm{pH}$ and SMC under the biochar treatments directly reduced a physiological constraint on soil bacteria and fungi and changed interactive relationships [28, 29]. Alternatively, soil $\mathrm{pH}$ is often significantly related to a variety of soil properties (e.g., nutrient availability and organic carbon characteristics) and indirectly regulates the microbial network structure [30]. Biochar amendments reshaped the distinct keystone taxa within the bacterial and fungal networks. The bacterial and fungal communities with keystone taxa indicated the complex interactions in the co-occurrence networks. The important keystone taxa in the phyla Actinobacteria and Gemmatimonadetes are capable of growing preferentially on carbon-rich refractory materials to decompose the cellulose, lignocellulose, and chitin in biochar-amended soils [31]. However, it should be noted that soil $\mathrm{pH}$ varied in a narrow range under the non-amended (5.71-6.02) and biochar-amended (6.14-6.57) treatments, respectively 
(Additional file 1: Table S1). SEM suggested that $\mathrm{pH}$ had a significant effect on fungal diversity rather than on bacterial diversity, when soil $\mathrm{pH}$ span a narrow range at nearly neutral value (Fig. 6). Bacteria and fungi exhibit fine differences in body size, metabolic activity, and dispersal potential [32], which display different responses to the narrow $\mathrm{pH}$ changes. The "size-plasticity" hypothesis argues that smaller individuals are less environment filtered than larger individuals, because smaller individuals are more likely to have plasticity in metabolic abilities [33,34]. Therefore, bacteria may exist widely in such a narrow $\mathrm{pH}$ range, suggesting that the selection pressure of $\mathrm{pH}$ was invisible on the bacterial community.

\section{Competition with keystone taxa stimulated the bacterial and fungal diversity}

To advance the explanatory and predictive understanding of SOC sequestration, it is critical to investigate how the underlying bacterial and fungal communities shift in their diversity. Traditional dichotomy supports the divergent natural selection generated by resource competition as a vital driver of rapid diversification, especially when microbial taxa share similar resource requirements or niches in the soil microenvironment [35]. Functional and phylogenetic diversity is commonly expected to be promoted by intra- and inter-specific competitive interaction in the ecological communities [36]. We found that the effects of biochar on the bacterial and fungal diversity are potentially mediated by keystone taxa in the networks (Fig. 6, Table 1). We postulated that high microbial diversity was sustained via the recruitment of particular keystone taxa from the indigenous taxa pool in the biochar-amended soils. It is generally assumed that the uneven distribution of interaction strengths is prevalent in the networks [37]. For instance, special taxa are likely to have close connections and thereby make stronger contributions to network structure and diversity relative to poorly connected taxa [38]. The highly connected keystone taxa in the networks can individually explain microbiome compositional turnover better than all taxa combined, highlighting crucial roles for maintaining the organization integrity and the functioning of the entire microbial community $[39,40]$. With network topological data, the members of the genera Arthrobacter and Chaetomium categorized as keystone taxa were exclusively observed in the bacterial and fungal networks under the biochar amendments, respectively. When the biochar-amended networks were compartmentalized into modules, the bacterial and fungal keystone taxa probably displayed intense competition with contacted members in the respective modules (Figs. 3 and 4). These presumed keystone taxa, Arthrobacter and Chaetomium, have competitive traits and advantages for breaking down recalcitrant biochar-derived $\mathrm{C}$ and capturing limiting resources more efficiently [41, 42]. Furthermore, the genus Penicillium could produce antifungal toxins to kill, inhibit growth, and displace competing fungi, forming antagonistic structures in the modules. Alternatively, multiple taxa with different competitive strategies and trait expression alter their morphology, trait expression, and metabolism to persist against direct displacement or overgrowth in diverse communities [18]. Network-based scores complemented with DNA-SIP microcosms provided consistent evidence of inter-specific competition by keystone taxa with continual increases in the bacterial and fungal diversity. Collectively, these results suggested that functional keystone taxa with mutually exclusive ability may increase bacterial and fungal diversity under the biochar amendments.

\section{Higher bacterial and fungal diversity decreased SOC mineralization}

The increases in bacterial and fungal diversity could be of ecological significance, as greatly reduced microbial carbohydrate catabolism and $q \mathrm{CO}_{2}$ were observed under the $\mathrm{MB}$ and $\mathrm{HB}$ amendments. The present study suggested that negative SOC priming was positively correlated with increased bacterial and fungal diversity. Despite soil $\mathrm{pH}$ and moisture have been reported as crucial drivers of SOC dynamics, soil bacterial and fungal communities are a core backbone of terrestrial SOC cycling, mediating the vast majority of SOC mineralization. There is an ongoing controversy over whether the modern ecological concept and theory of biodiversity-ecosystem functioning relationships hold true for microorganisms [43]. Essentially, the reported impacts of microbial diversity on SOC dynamics vary considerably, ranging from being negative over neutral to positive. The functional traits of keystone taxa have frequently been proposed to be of particular ecological importance to determine the relationships between taxa richness and SOC dynamics [44, 45]. The keystone taxa often serve as gatekeepers to community functions, with profound contributions to SOC transformation and sequestration [46].

Biochar can facilitate negative SOC priming in the long term due to lowering the microbial mineralization rate of natural SOC $[47,48]$. The overall diversity of bacterial and fungal communities was negatively associated with microbial carbohydrate catabolism and $q \mathrm{CO}_{2}$ (Fig. 6, Additional file 1: Table S3). Theoretically, the competitive interaction in the networks can powerfully determine the direction and magnitude of the diversityfunction relationships [49]. Although the role of competition was relatively weak in the entire network, the competitive interaction with keystone taxa may outweigh any positive effects of highly co-existing taxa on SOC dynamics under the biochar amendments (Figs. 3, 4 and 5). 
We confirmed that the biochar-induced competitive interaction with keystone taxa benefited SOC accumulation by inhibiting of carbohydrate catabolism and $q \mathrm{CO}_{2}$. In marked contrast, the non-amended networks exhibited a pairwise positive relationship with keystone taxa. Co-existing taxa with cooperative interactions may stimulate community performance relevant to increasing SOC mineralization. A new set of experimental studies with synthesized microcosms has demonstrated that high richness (more than ten species) enhances the inhibitory force of competitors with the capability to dampen SOC use efficiency $[18,50]$. The soil has typically extremely high diversity in the bacterial and fungal communities, where competitive stress associated with inter-specific interactions may likewise contribute to the eventual suppression of carbon catabolic rates in the natural field systems $[43,51]$. Nevertheless, it should be noteworthy that competitive relationships do not inevitably correspond to "poor" ecosystem functioning. Reduced carbon metabolism and SOC mineralization rates with increasing bacterial and fungal diversity could stimulate SOC retention under the biochar amendments. Taken together, our results favored the previous inference that the intensely competitive or antagonistic interactions could impair the community performance of SOC mineralization at high levels of diversity. More broadly, the predictions of how SOC mineralization varies with microbial diversity will enrich our knowledge of the mechanism underlying the diversity-function patterns in diverse microbial communities.

\section{Conclusions}

In conclusion, biochar amendments induced negative priming effects on SOC sequestration by competitive interaction coupled with keystone taxa in the microbiome networks. Biochar amendments structured the competition with keystone taxa in the bacterial and fungal networks, which promoted microbial diversity and subsequently reduced carbohydrate catabolism and $q \mathrm{CO}_{2}$. Our study highlighted the important role of biochar-induced competition with keystone taxa in stimulating SOC sequestration via negative priming. This finding will stimulate the novel theoretical developments for the priming effect on SOC dynamics.

\section{Methods}

\section{Field experiment description}

The field experiment was conducted at the tobacco field station ( $\left.35^{\circ} 51^{\prime} 36^{\prime \prime} \mathrm{N}, 118^{\circ} 37^{\prime} 48^{\prime \prime} \mathrm{E}\right)$, located in Linyi, Shandong Province, China. This site has a temperate monsoon climate with an annual average temperature and precipitation of $14.1{ }^{\circ} \mathrm{C}$ and $849 \mathrm{~mm}$, respectively. The tested soil is characterized as a Hapli-Ustic Cambisol in the Food and Agricultural Organization (FAO) classification system. Fifteen trial plots $(5 \mathrm{~m}$ long $\times 2 \mathrm{~m}$ wide) were laid out in a completely randomized block including five treatments with three replicates: (1) no fertilizer (CK), (2) conventional fertilization (CF), (3) low biochar with $2400 \mathrm{~kg}$ $\mathrm{ha}^{-1}$ year $^{-1}$ (LB), (4) medium biochar with $7200 \mathrm{~kg} \mathrm{ha}^{-1}$ year $^{-1}$ (MB), and (5) high biochar with $12,000 \mathrm{~kg} \mathrm{ha}^{-1}$ year $^{-1}(\mathrm{HB})$. The CF treatment contained $450 \mathrm{~kg} \mathrm{ha}^{-1}$ compound fertilizer $\left(10-10-30, \quad \mathrm{~N}-\mathrm{P}_{2} \mathrm{O}_{5}-\mathrm{K}_{2} \mathrm{O}\right), 600 \mathrm{~kg} \mathrm{ha}^{-1}$ fermented soybean meal, and $150 \mathrm{~kg} \mathrm{ha}^{-1} \mathrm{~K}_{2} \mathrm{SO}_{4}$. Three biochar amendments were given the equal application rates of nitrogen, phosphorus, and potassium as those under the $\mathrm{CF}$ treatment. The biochar used in the experiment was produced from maize straw pyrolyzed at $450^{\circ} \mathrm{C}$ for $48 \mathrm{~h}$. The biochar had a $\mathrm{pH}$ value of 9.49 , SOC of $915.4 \mathrm{~g} \mathrm{~kg}^{-1}$, total nitrogen of $2.32 \mathrm{~g} \mathrm{~kg}^{-1}$, total phosphorus of $3.03 \mathrm{~g} \mathrm{~kg}^{-1}$, total potassium of $32.94 \mathrm{~g} \mathrm{~kg}^{-1}$, available phosphorus of 336.24 $\mathrm{mg} \mathrm{kg}-1$, available potassium of $18,125 \mathrm{mg} \mathrm{kg}^{-1}$, and cation exchange capacity of $15.06 \mathrm{cmol} \mathrm{kg}^{-1}$. Tobacco (Nicotiana tabacum L., cultivar NC102) grown in a monoculture was transplanted in May and harvested in August since 2014. Briefly, tillage and ridging were conducted 1 week before the tobacco seedling transplanting. Healthy seedling transplanting was performed with a population density of 18,000 plants per hectare in each field plot. Technical guidelines for the management of tobacco crops were applied during the whole growth season. We manually removed the grass at the rosetting stage, snapped the tobacco flowers at the topping stage, and harvested mature leaves from bottom to top of the stalks at the maturity stage. Tobacco crops were harvested three times at weekly interval.

\section{Soil sampling and physicochemical properties}

Soil samples from each plot were collected at a depth of $0-20 \mathrm{~cm}$ after the harvest in early August 2016. After field collection, fresh samples were placed on ice and immediately transported to the laboratory, where they were sieved $(2 \mathrm{~mm})$ to remove visible residues and then homogenized. Soil samples were subdivided into three subsamples for analyzing soil physiochemical properties, microbial communities and functions, and DNA-SIP microcosms.

Soil $\mathrm{pH}$ was detected by a glass electrode with water: soil ratio of 2.5:1 $(v / w)$. SOC was determined by wet digestion using the potassium dichromate method [52]. Total nitrogen and available nitrogen were measured using the micro-Kjeldahl method and the alkaline hydrolysis diffusion method, respectively [53, 54]. Total phosphorus was digested with $\mathrm{HF}-\mathrm{HClO}_{4}$ and available potassium was extracted with sodium bicarbonate, respectively, which were determined using the molybdenum-blue method [55, 56]. Total potassium was digested with $\mathrm{HF}-\mathrm{HClO}_{4}$ and available potassium was extracted with ammonium acetate, respectively, which were detected by atomic absorption spectrophotometer [57]. Cation 
exchange capacity was measured by ammonium acetate solution at $\mathrm{pH} 7$ [58]. Bulk density was determined by the standard cylinders of $43 \mathrm{~cm}^{3}$. Soil water characteristic curve was measured at $0,0.0025,0.006,0.01,0.03$, 0.1 , and $1.5 \mathrm{MPa}$ using the pressure membrane meter method [59]. Soil moisture capacity (SMC) are calculated by progressive summation of pore volumes fractions based on soil water characteristic curve, accomplished by pairing each calculated pore volume fractions with the equivalent pore radius [60].

\section{PLFA profiles}

To address question 1, we characterized microbial biomass by PLFA analysis following a modified method [61]. Briefly, total lipids were extracted from $2 \mathrm{~g}$ freeze-dried soil samples with a chloroform-methanol-citrate buffer mixture (1:2:0.8, v/v/v) and separated into neutral, glycoand phospholipids by a silica acid column. Phospholipids were subjected to a mild alkaline methanolysis, and the fatty acid methyl esters were quantified by a HP 6890 Series gas chromatograph instrument (Hewlett Packard, Wilmington, DE, USA). Identification was performed using bacterial fatty acid standards and MIDI peak identification software (Microbial ID Inc., Newark, DE, USA). Microbial biomass was calculated by summing the abundance of specific biomarkers and expressed as nmol PLFA g ${ }^{-1}$ dry soil [62]. The following PLFAs were representative markers of the specific groups: Gram-negative bacteria (cyclopropyl bacteria and unsaturated PLFAs) [63], Gram-positive bacteria (iso- and anteiso-branched PLFAs) [63], actinomycetes (10Me PLFAs) [64], and fungi $(18: 1 \omega 9 \mathrm{c}$ and $18: 2 \omega 6,9 \mathrm{c})$ [62]. The sum of Gram-positive bacteria, Gram-negative bacteria, and non-specific bacteria was expressed as the bacterial biomass [62].

\section{Illumina sequencing and bioinformatic analysis}

To address question 1, we determined the diversity, composition, and network by Illumina sequencing of $16 \mathrm{~S} r R N A$ and ITS genes. The samples for analyzing the microbial communities were stored at $-80^{\circ} \mathrm{C}$ until DNA extraction. The DNA was extracted from $0.25 \mathrm{~g}$ soil samples using a PowerSoil DNA extraction kit (MoBio Laboratories Inc., Carlsbad, CA, USA) following the manufacturer's instructions. The extracted DNA was suspended in nuclease-free TE buffer, and the quality and quantity of DNA were checked using a NanoDrop ND-1000 spectrophotometer (NanoDrop Technologies, Wilmington, DE, USA). For the high-throughput Illumina sequencing, PCR amplifications of the bacterial $16 \mathrm{~S} r R N A$ and fungal ITS genes were performed using the universal primer pairs of 338F/806R [65] and ITS1-1737F/ ITS2-2043R, respectively [66]. Both the forward and reverse primers were tagged with an adapter and linker sequence, and 8-bp barcode oligonucleotides were added to distinguish the amplicons from different soil samples. Reaction mixtures $(20 \mu \mathrm{L})$ contained $4 \mu \mathrm{L}$ of $5 \times$ FastPfu Buffer, $0.25 \mu \mathrm{L}$ of each primer $(10 \mu \mathrm{M}), 2 \mu \mathrm{L}$ of $2.5 \mathrm{mM}$ dNTPs, $10 \mathrm{ng}$ template DNA, and $0.4 \mu \mathrm{L}$ FastPfu Polymerase. The PCR protocol was as follows: an initial pre-denaturation at $95^{\circ} \mathrm{C}$ for $5 \mathrm{~min} ; 28$ cycles of $30 \mathrm{~s}$ at 94 ${ }^{\circ} \mathrm{C}, 30 \mathrm{~s}$ at $55^{\circ} \mathrm{C}$, and $45 \mathrm{~s}$ at $72{ }^{\circ} \mathrm{C}$; and a final extension at $72^{\circ} \mathrm{C}$ for $10 \mathrm{~min}$. All amplicons were cleaned and pooled in equimolar concentrations in a single tube, after which they were subjected to library preparation, cluster generation, and 250-bp paired-end sequencing on an Illumina MiSeq platform (Illumina Inc., San Diego, CA, USA).

The raw sequences were quality screened and trimmed using the Quantitative Insights into Microbial Ecology (QIIME package version 1.9.1) pipeline [67]. Sequences that fully matched the barcodes were selected and distributed into separate files for the bacterial 16S rRNA and fungal ITS genes. Additional sequence processing was performed including quality trimming, demultiplexing, and taxonomic assignments. QIIME quality trimming was performed in accordance with the following criteria: (1) truncated before three consecutive low-quality bases and re-evaluated for length, (2) no ambiguous bases, and (3) the minimum sequence length of $469 \mathrm{bp}$ (16S rRNA) and $307 \mathrm{bp}$ (ITS) after trimming. The assembled reads were processed de novo chimera detection conducted with UCHIME [68]. The remaining sequences were additionally screened for frame shifts via HMM-FRAME [69]. Thereafter, the sequence reads from each sample were clustered to provide similarity-based operational taxonomic units (OTUs) that had 97\% identity cutoffs [70]. Finally, the sequences of $16 \mathrm{~S} r R N A$ and ITS genes were subjected to a similarity search using the Basic Local Alignment Search Tool (BLAST) of the Silva Release 119 database and UNITE version 6.0 database, respectively [71, 72]. Alpha diversity and Bray-Curtis distances for a principal coordinate analysis of soil microbial community were calculated after rarefying all samples to the same sequencing depth.

\section{DNA stable isotope probing microcosms and quantitative PCR}

To address question 2, we determined the impacts of soil bacterial and fungal networks coupled with keystone taxa on microbial diversity by DNA-stable isotope probing (SIP) microcosms and qPCR. Subsamples were gathered for each treatment from the portion that was stored at $-80^{\circ} \mathrm{C}$. Microcosms with $20 \mathrm{~g}$ fresh soil were established in $50 \mathrm{~mL}$ sterilized glass serum vials, which were sealed with membrane to allow for air exchange. Microcosms were separated into duplicate groups that were supplemented with $10 \mathrm{mM}{ }^{12} \mathrm{C}$ - or ${ }^{13} \mathrm{C}$-labeled glucose, and then incubated at $28^{\circ} \mathrm{C}$ for 15 days. The 
${ }^{13} \mathrm{C}$-labeled glucose was universally labeled by ${ }^{13} \mathrm{C}$ atoms at all carbons (>99\% atom purity, Cambridge Isotope Laboratories, Andover, MA, USA). The isolation of density-gradient fractions of microcosm DNA samples was performed following Dunford and Neufeld [73]. Briefly, an appropriate volume of gradient buffer was added to $2 \mu \mathrm{g}$ of total DNA and $4.8 \mathrm{~mL}$ of $7.163 \mathrm{M}$ cesium chloride $(\mathrm{CsCl})$ density-gradient solution mix in a $15-\mathrm{mL}$ Falcon tube, and the solution was adjusted to a final density of $1.725 \mathrm{~g} \mathrm{~mL}^{-1}$. The solution was transferred into $5 \mathrm{~mL}$ Quick-Seal polyallomer centrifuge tubes that were sealed to ensure tube quality. Then, the tubes were weighed, balanced, and loaded into a TLA-120.2 rotor and centrifuged at 45,000 rpm for $44 \mathrm{~h}$ under vacuum using a Beckman optima TLX (Beckman Coulter, Inc., Palo Alto, CA, USA). After ultracentrifugation, the solution was immediately separated into 15 fractions from the bottom of each tube using a calibrated infusion pump (New Era Pump System, Inc., Farmingdale, NY, USA). Samples from unlabeled control experiments were always analyzed in parallel as negative controls. ${ }^{12} \mathrm{C}$ controls were extremely useful to identify the "heavy" DNA from SIP incubations [74]. The DNA present in each fraction was purified on a MicroCon YM-30 column (Millipore) to remove $\mathrm{CsCl}$ and dissolved in $30 \mu \mathrm{L}$ nuclease-free $\mathrm{H}_{2} \mathrm{O}$. The pooled heavy density fractions with buoyant densities from 1.725 to $1.750 \mathrm{~g} \mathrm{~mL}^{-1}$ were used for $\mathrm{qPCR}$ and Illumina sequencing after incubation of the ${ }^{12} \mathrm{C}$ - and ${ }^{13} \mathrm{C}$-labeled glucose. On average, the heavy density fractions in the ${ }^{13} \mathrm{C}$-incubated samples contained over 12 times more DNA than those in the ${ }^{12} \mathrm{C}$-controls for the non-amended microcosms and over 6 times than those for the biocharamended microcosms.

The copy numbers of $16 \mathrm{~S} r R N A$ and ITS genes in the fractioned DNA of each fraction were quantified by qPCR on a CFX96 Optical Real-Time Detection System (Bio-Rad Laboratories, Hercules, CA, USA) using the same primers as described above. Reaction mixtures $(20 \mu \mathrm{L})$ contained $1 \mu \mathrm{L}$ DNA template (1-10 ng), $10 \mu \mathrm{L} 2 \times$ SYBR Premix Ex Taq (TaKaRa, Dalian, China), and $0.5 \mu \mathrm{M}$ each primer. No-template controls were included with each qPCR run. Standard curves were constructed by a serial dilution $\left(10^{2}\right.$ to $10^{8}$ copies) of plasmids harboring $16 \mathrm{~S}$ rRNA and ITS genes. All qPCR assays were run with 3 min initial denaturation at $95^{\circ} \mathrm{C}$, followed by 40 cycles, with plate-reading, of $30 \mathrm{~s}$ at $95^{\circ} \mathrm{C}$ and $45 \mathrm{~s}$ at $60^{\circ} \mathrm{C}$, and then with a final melt-curve step from 72 to $95^{\circ} \mathrm{C}$. The qPCR was performed in triplicate, and amplification efficiencies $>97 \%$ were obtained with the $r^{2}$ values $>0.99$.

\section{Microbial carbon metabolic profiles and soil metabolic quotient}

To address question 3, we measured microbial carbon metabolic activities using Biolog EcoPlates and determined $q \mathrm{CO}_{2}$ as soil respiration divided by microbial biomass. The capability of soil microbial community to utilize a variety of carbon sources was measured with Biolog EcoPlates (Biolog Inc., Hayward, CA, USA) [75]. The Biolog EcoPlates consisted of 96-well microplates, containing 31 different carbon sources plus a blank well including three replications. Carbon sources were subdivided into six group substrates including carbohydrates, carboxylic acids, amino acids, polymers, phenolic acid, and amines/amides [76]. Soil microorganisms were extracted as follows: $5 \mathrm{~g}$ soil (dry weight equivalent) was added to $45 \mathrm{~mL}$ sterile $0.85 \%(w / v)$ saline solution. The mixture was shaken for $30 \mathrm{~min}$ at $90 \mathrm{rpm}$ and then left to stand for $30 \mathrm{~min}$. Next, $1 \mathrm{~mL}$ supernatant was diluted to $20 \mathrm{~mL}$ with sterile saline solution. Then, each well of the Biolog EcoPlates was inoculated by $200 \mu \mathrm{L}$ of the prepared suspension and incubated at $25^{\circ} \mathrm{C}$ in the dark for 7 days. The rate of utilization of the carbon sources was pointed by the reduction of tetrazolium violet redox dye, and color development reflecting carbon utilization in the wells was detected by absorbance measurements at $590 \mathrm{~nm}$ every $24 \mathrm{~h}$. For the posterior analysis, absorbance at a single time point ( $96 \mathrm{~h}$ ) was used, when the asymptote was reached. Optical density $\left(\mathrm{OD}_{590}\right)$ value from each well was corrected by subtracting the control (blank well) values.

Soil respiration was determined according to the modified method described by Chen et al. [77]. Briefly, $25 \mathrm{~g}$ soil (dry weight equivalent) was moistened to $60 \%$ water-holding capacity and incubated in a $125-\mathrm{mL}$ jar under aerobic conditions at $25^{\circ} \mathrm{C}$. All the jars were kept at the same conditions as the pre-incubation during a period of 7 days. Three replicates of gas samples from each treatment were collected from the headspace of the jars using a gas-tight syringe at $0.5,1,3,5,7,10,15,20,25$, and 30 days during the incubation period. After gas sampling, stoppers were removed from the jars, and aluminum foil was used to seal the jars again. The $\mathrm{CO}_{2}$ concentration was analyzed with a HP 6890 Series gas chromatography (Hewlett Packard, Wilmington, DE, USA) equipped with a flame ionization detector. Three extra jars containing the same weight of pure silica sand were analyzed in parallel as blanks. $\mathrm{CO}_{2}$ gas standards were purchased from the National Research Center for Certified Reference Materials, China. The $q \mathrm{CO}_{2}$ was calculated as soil basal respiration divided by total microbial biomass.

\section{Statistical analysis}

One-way analysis of variance (ANOVA) was performed to assess the effects of fertilization treatments on soil properties, the diversity and abundances of soil bacterial and fungal communities, and microbial carbon metabolism and $q \mathrm{CO}_{2}$ using Bonferroni's post hoc test in SPSS 20.0 software (SPSS, Chicago, IL, USA). The significance testing in one-way ANOVA was based on the data from which the samples originated both followed a normal 
distribution and had the same variances [78]. Principal coordinate analysis ( $\mathrm{PCoA}$ ) was used to evaluate the biochar impacts on the Bray-Curtis distances of the bacterial and fungal community compositions [79]. We conducted the "capscale" function of the $\mathrm{R}$ package vegan (version 3.1.2) to calculate the Bray-Curtis dissimilarities for principal coordinate analysis and "permutest" permutation-based testing for the calculation of the significance values [80]. The compositional similarity was calculated as 1 minus the Bray-Curtis dissimilarity.

The non-amended (CK and $\mathrm{CF}$ ) and biochar-amended ( $L B, M B$, and $H B$ ) samples were separately examined for biochar effects on soil bacterial and fungal networks. The OTUs presented either in all non-amended or in all biochar-amended samples were kept for the subsequent network constructions, respectively. The co-occurrence patterns of the bacterial and fungal communities were constructed by calculating multiple correlations and similarities with co-occurrence network (CoNet) inference [81]. We used an ensemble approach based on the four measurements, including Pearson and Spearman correlations and Bray-Curtis and Kullback-Leibler dissimilarities between pairwise OTUs. A valid co-occurrence was considered a statistically robust correlation between taxa when the correlation threshold was above 0.7 and the $P$ value was below 0.01 . The $P$ values were merged using Brown's method for the four measurements [82] and then adjusted using the Benjamini-Hochberg procedure to reduce the chances of obtaining false-positive results [83]. Network visualization was conducted using Gephi software [84]. Nodes indicated individual microbial taxa (OTUs) in the microbiome network [26]. Network edges represented the pairwise correlations between nodes, suggesting a biologically or biochemically meaningful interactions [12]. The modules were the clusters of closely interconnected nodes (i.e., groups of co-existing or coevolving microbes) [26]. The microbial networks were searched to identify highly associated nodes (clique-like structures) using Molecular Complex Detection (MCODE) introduced for the Cytoscape platform [85]. The algorithm identifies seeded nodes for expansion by computing a score of local density for each node in the graph. Over $90 \%$ accuracy of MCODE predictions yielded, when an overlap score was above 0.2 threshold. The calculated topological characteristics of the bacterial and fungal networks included the following: the numbers of positive and negative correlations, average path length, graph density, network diameter, average clustering coefficient, average connectivity, and modularity. The roles of individual nodes were estimated by two topological parameters: the within-module connectivity $Z$, which quantified to what extent a node connected to other nodes in its own module, and the among-module connectivity $P$, which quantified how well the node connected to different modules [86]. The nodes with either a high value of $Z$ or $P$ were defined as keystone taxa, including module hubs $(Z>0.25, P \leq 0.62$; critical to its own module coherence), connectors $(Z \leq 0.25, P>0.62$; connect modules together and important to network coherence), and network hubs ( $Z>0.25, P>0.62$; vital to both the network and its own module coherence) [87]. For network modules, the module eigengene could summarize the closely connected members within a module [88]. The singular value decomposition of the module expression matrix was used to represent the module eigengene networks [89]. The module eigengene of a module was defined as the first principal component of the standardized module expression data [90]. Then, the relationships between soil properties, microbial diversity, network module eigengenes, and SOC mineralization (microbial carbon metabolism and $q \mathrm{CO}_{2}$ ) were evaluated using Spearman's rank correlation test.

Random forest modeling was used to quantitatively assess the important predictors of carbohydrate catabolism and $q \mathrm{CO}_{2}$ involving soil properties and the microbial community. Soil properties included soil pH, SMC, SOC, total nitrogen, total phosphorus, total potassium, available nitrogen, available phosphorus, available potassium, and cation exchange capacity, while the microbial community included the biomass, diversity, composition, and network of soil bacterial and fungal communities. The bacterial and fungal biomass were characterized by bacterial and fungal PLFAs. The bacterial and fungal diversities were represented by the Shannon index based on the rarified same sequencing depth. The compositions of soil bacterial and fungal communities were indicated by the first principal coordinates (PCoA1). The bacterial and fungal networks were represented by the module eigengenes that were significantly related to diversity and carbohydrate metabolism. The importance of each factor was evaluated by the increase in the mean square error between the observed and predicted values when the predictor was randomly permuted [91]. This accuracy of importance was measured for each tree and was averaged across the forest. Accuracy of importance was estimated for each observation using the left-out individual predictions (called "out-of-bag" estimation) and then averaged over all observations [92]. These analyses were conducted using the randomForest package [93], and the significance of the model and predictor importance was determined using the $\mathrm{A} 3$ and rfPermute packages, respectively [94, 95]. Structural equation modeling (SEM) was applied to determine the direct and indirect contributions of soil properties and microbial community to carbohydrate catabolism and $q \mathrm{CO}_{2}$ [96]. SEM analysis was conducted via the robust maximum likelihood evaluation method using AMOS 20.0 (AMOS IBM, USA). The SEM fitness was examined on the basis of a non-significant chi-square test $(P>0.05)$, the goodness-of-fit index (GFI), and the root mean square error of approximation (RMSEA) [97]. 


\section{Additional file}

Additional file 1: Figure S1. Soil water characteristic curves (a) and equation diameter of pore versus water content $(b, d-\theta)$ curves under nonamended and biochar-amended treatments in the field experimnet. Figure S2. Effects of biochar amendments on total phospholipid fatty acid (PLFA) and various microbial specific groups in the field experimnet. Figure S3. Taxonomic compositions of bacterial (a) and fungal (b) communities under non-amended and biochar-amended treatments in the field experimnet. Figure S4. Biochar amendments alter the bacterial (a) and fungal (b) community composition in the field experimnet. Figure S5. Mean predictor importance of soil properties and the biomass, diversity, composition, and networks of the bacterial and fungal communities on carbohydrate utilization (a) and soil metabolic quotient (b) based on random forest modeling. Figure S6. Biochar treatments alter the bacterial $(a, b)$ and fungal $(c, d)$ diversity in the conducted stable isotope probing microcosms. Figure S7. Taxonomic compositions of bacterial (a) and fungal (b) communities in the conducted stable isotope probing microcosms. Table S1. Soil physicochemical properties condition under five treatments. Table S2. Topological properties of co-occurring bacterial and fungal networks obtained under biochar non-amended and amended treatments in the field experiment and stable isotope probing incubations. Table S3. Correlations of soil properties, the biomass and diversity of bacterial and fungal communities, carbohydrate catabolism, and soil metabolic quotient $\left(q \mathrm{CO}_{2}\right)$. (DOCX $\left.1022 \mathrm{~kb}\right)$

\section{Acknowledgements}

We thank J. Su, H Zong, J. Yang, and Y. Yang for their assistance in soil sampling and lab analyses.

\section{Funding}

This research was financially supported by the National Key R\&D Project (2016YFD0200309), Strategic Priority Research Program and Key Project of CAS (XDB15030201, KFZD-SW-112), Distinguished Youth Scholar Program of Jiangsu Province (BK20180049), National Natural Science Foundation of China (41771297), Natural Science Foundation of Jiangsu Province (BK20171520), the Youth Innovation Promotion Association of CAS (2017361), and the Modern Agricultural Industry Technology System of the Ministry of Agriculture of China (CARS-22-G-14)

\section{Availability of data and materials}

The sequences of 16S rRNA and ITS genes were deposited in the Sequence Read Archive (SRA) at NCBI under Bioprojects PRJNA506120 (Biosamples SAMN10440406-SAMN10440420 and SAMN10440421-SAMN10440450 for the field and incubation experiment) and PRJNA506286 (Biosamples SAMN10449102-SAMN10449116 and SAMN10449117-SAMN10449146 for the field and incubation experiment), respectively.

\section{Authors' contributions}

LC, YJ, and BS designed all the experiments and wrote the manuscript. LC and $Y J$ were responsible for performing the field and lab experiments. All authors analyzed all data, discussed the results, critically reviewed the manuscript, and approved its publication.

Ethics approval and consent to participate Not applicable.

\section{Consent for publication}

Not applicable.

\section{Competing interests}

The authors declare that they have no competing interests.

\section{Publisher's Note}

Springer Nature remains neutral with regard to jurisdictional claims in published maps and institutional affiliations.

\section{Author details}

State Key Laboratory of Soil and Sustainable Agriculture, Institute of Soil Science, Chinese Academy of Sciences, No. 71 East Beijing Road, Nanjing 210008, China. ${ }^{2}$ Institute of Applied Ecology, Chinese Academy of Sciences, Shenyang 110016, China. ${ }^{3}$ Zhejiang Provincial Key Laboratory of Agricultural Resources and Environment, Institute of Soil and Water Resources and Environmental Science, Zhejiang University, Hangzhou 310058, China. ${ }^{4}$ College of Life Science, Nanjing Normal University, Nanjing 210023, China. ${ }^{5}$ School of Geography Science, Nanjing Normal University, Nanjing 210023, China. ${ }^{6}$ University of Chinese Academy of Sciences, Beijing 100049, China.

Received: 16 December 2018 Accepted: 8 May 2019

Published online: 20 May 2019

\section{References}

1. Lehmann J, Kleber M. The contentious nature of soil organic matter. Nature. 2015;528:60-8.

2. Lehmann J, Rillig MC, Thies J, Masiello CA, Hockaday WC, Crowley D. Biochar effects on soil biota - a review. Soil Biol Biochem. 2011;43:1812-36.

3. Maestrini B, Herrmann AM, Nannipieri P, Schmidt MWl, Abiven S. Ryegrassderived pyrogenic organic matter changes organic carbon and nitrogen mineralization in a temperate forest soil. Soil Biol Biochem. 2014;69:291-301.

4. Luo Y, Durenkamp M, Nobili MD, Lin Q, Brookes PC. Short term soil priming effects and the mineralisation of biochar following its incorporation to soils of different pH. Soil Biol Biochem. 2011;43:2304-14.

5. Keith A, Singh B, Dijkstra FA. Biochar reduces the rhizosphere priming effect on soil organic carbon. Soil Biol Biochem. 2015;88:372-9.

6. Zheng H, Wang X, Luo X, Wang Z, Xing B. Biochar-induced negative carbon mineralization priming effects in a coastal wetland soil: roles of soil aggregation and microbial modulation. Sci Total Environ. 2018;610:951-60.

7. Whitman T, Peperanney C, Enders A, Koechli C, Campbell A, Buckley DH, et al. Dynamics of microbial community composition and soil organic carbon mineralization in soil following addition of pyrogenic and fresh organic matter. ISME J. 2016;10:2918-30.

8. Yu Z, Chen L, Pan S, Li Y, Kuzyakov Y, Xu J, Brookes PC, et al. Feedstock determines biochar-induced soil priming effects by stimulating the activity of specific microorganisms. Eur J Soil Sci. 2018;69:521-34.

9. Schimel JP, Schaeffer M. Microbial control over carbon cycling in soil. Front Microbiol. 2012:3:348.

10. Liang C, Schimel JP, Jastrow JD. The importance of anabolism in microbial control over soil carbon storage. Nat Microbiol. 2017;2:17105.

11. Zimmerman AR, Gao B, Ahn M-Y. Positive and negative carbon mineralization priming effects among a variety of biochar-amended soils. Soil Biol Biochem. 2011;43:1169-79.

12. Weiss S, Van TW, Lozupone C, Faust K, Friedman J, Deng Y, et al. Correlation detection strategies in microbial data sets vary widely in sensitivity and precision. ISME J. 2016;10:1669-81.

13. Berry D, Widder S. Deciphering microbial interactions and detecting keystone species with co-occurrence networks. Front Microbiol. 2014;5:1-14.

14. Herren CM, McMahon KD. Keystone taxa predict compositional change in microbial communities. Environ Microbiol. 2018;20:2207-17.

15. Yu J, Deem LM, Crow SE, Deenik JL, Penton CR. Biochar application influences microbial assemblage complexity and composition due to soil and bioenergy crop type interactions. Soil Biol Biochem. 2018; 117:97-107.

16. Gul S, Whalen JK, Thomas BW, Sachdeva V, Deng H. Physico-chemical properties and microbial responses in biochar-amended soils: mechanisms and future directions. Agr Ecosyst Environ. 2015;206:46-59.

17. Ghoul M, Mitri S. The ecology and evolution of microbial competition. Trends Microbiol. 2016:24:833-45.

18. Maynard DS, Bradford MA, Lindner DL, Diepen LTAV, Frey SD, Glaeser JA, et al. Diversity begets diversity in competition for space. Nat Ecol Evol. 2017:1:0156

19. van der Heijden MGA, Hartmann M. Networking in the plant microbiome. PLoS Biol. 2016:14:e1002378.

20. Becker J, Eisenhauer N, Scheu S, Jousset A. Increasing antagonistic interactions cause bacterial communities to collapse at high diversity. Ecol Lett. 2012;15:468-74.

21. Murray J, Keith A, Singh B. The stability of low- and high-ash biochars in acidic soils of contrasting mineralogy. Soil Biol Biochem. 2015;89:217-25. 
22. Novak JM, Busscher WJ, Watts DW, Amonette JE, Ippolito JI, Lima IM, et al. Biochars impact on soil-moisture storage in an ultisol and two aridisols. Soil Sci. 2012;177:310-20.

23. Downie A, Crosky A, Munroe P. Physical properties of biochar. In: Lehmann J, Joseph S, editors. Biochar for environment management: science and technology. Landon: Earthscan press; 2009. p. 13-32.

24. Žif̌cáková L, Baldrian P. Fungal polysaccharide monooxygenases: new players in the decomposition of cellulose. Fungal Ecol. 2012;5:481-9.

25. Maestrini B, Nannipieri P, Abiven S. A meta-analysis on pyrogenic organic matter induced priming effect. GCB Bioenergy. 2014;7:577-90.

26. Layeghifard M, Hwang DM, Guttman DS. Disentangling interactions in the microbiome: a network perspective. Trends Microbiol. 2017;25:217-28.

27. Jiang Y, Sun B, Li H, Liu M, Chen L, Zhou S. Aggregate-related changes in network patterns of nematodes and ammonia oxidizers in an acidic soil. Soil Biol Biochem. 2015:88:101-9.

28. Brady NC, Weil RR. The nature and properties of soil $\left(13^{\text {th }}\right.$ ed). Upper Saddle River, Prentice Hall, NJ; 2007.

29. Evans SE, Wallenstein MD. Climate change alters ecological strategies of soil bacteria. Ecol Lett. 2013;17:155-64.

30. Madigan MT, Martinko JM. Brock biology of microorganisms (11th ed). San Francisco, CA: Pearson Benjamin Cummings; 2006.

31. Khodadad CLM, Zimmerman AR, Green SJ, Uthandi S, Foster JS. Taxaspecific changes in soil microbial community composition induced by pyrogenic carbon amendments. Soil Biol Biochem. 2011;43:385-92.

32. Woodward G, Ebenman B, Emmerson M, Montoya JM, Olesen JM, Valido $A$, et al. Body size in ecological networks. Trends in Ecol Evol. 2005;20:402-9.

33. Finlay BJ. Global dispersal of free-living microbial eukaryote species. Science. 2002;296:1061-3.

34. Langenheder S, Lindström ES, Tranvik LJ. Weak coupling between community composition and functioning of aquatic bacteria. Limnol Oceanogr. 2005:50:957-67.

35. Freilich S, Zarecki R, Eilam O, Segal ES, Henry CS, Kupiec M, et al. Competitive and cooperative metabolic interactions in bacterial communities. Nat Commun. 2011;2:589.

36. Violle C, Nemergut DR, Pu Z, Jiang L. Phylogenetic limiting similarity and competitive exclusion. Ecol Lett. 2011;14:782-7.

37. O'Gorman EJ, Jacob U, Jonsson T, Emmerson MC. Interaction strength, food web topology and the relative importance of species in food webs. J Anim Ecol. 2010;79:682-92

38. Zhao L, Zhang H, O'Gorman EJ, Tian W, Ma A, Moore JC, et al. Weighting and indirect effects identify keystone species in food webs. Ecol Lett. 2016;19:1032-40.

39. Banerjee S, Schlaeppi K, Mga VDH. Keystone taxa as drivers of microbiome structure and functioning. Nat Rev Microbiol. 2018;16:567-76.

40. Jiang YJ, Li SZ, Li RP, Zhang J, Liu YH, Lv LF, et al. Plant cultivars imprint the rhizosphere bacterial community composition and association networks. Soil Biol Biochem. 2017;109:145-55

41. Fan F, Yin C, Tang Y, Li Z, Song A, Wakelin SA, et al. Probing potential microbial coupling of carbon and nitrogen cycling during decomposition of maize residue by ${ }^{13} \mathrm{C}-\mathrm{DNA}$-SIP. Soil Biol Biochem. 2014;70:12-21.

42. Harreither W, Sygmund C, Augustin M, Narciso M, Rabinovich ML, Gorton L, et al. Catalytic properties and classification of cellobiose dehydrogenases from ascomycetes. Appl Environ Microbiol. 2011;77:1804-15.

43. Bardgett RD, van der Putten WH. Belowground biodiversity and ecosystem functioning. Nature. 2014;515:505-11.

44. McGuire KL, Treseder KK. Microbial communities and their relevance for ecosystem models: decomposition as a case study. Soil Biol Biochem. 2010;42:529-35.

45. Nielsen UN, Ayres E, Wall DH, Bardgett RD. Soil biodiversity and carbon cycling: a review and synthesis of studies examining diversity-function relationships. Eur J Soil Sci. 2011;62:105-16.

46. Lynch MDJ, Neufeld JD. Ecology and exploration of the rare biosphere. Nat Rev Microbiol. 2015:13:217-29.

47. Cheng H, Hill PW, Bastami MS, Jones DL. Biochar stimulates the decomposition of simple organic matter and suppresses the decomposition of complex organic matter in a sandy loam soil. GCB Bioenergy. 2017:9:1110-21.

48. Weng Z, Zwieten LV, Singh BP, Tavakkoli E, Joseph S, Macdonald LM, et al. Biochar built soil carbon over a decade by stabilizing rhizodeposits. Nat Clim Change. 2017;7:371-6.
49. Hooper D, Chapin F, Ewel JJ, Hector A, Inchausti P, Lavorel S, Lawton JH, et al. Effects of biodiversity on ecosystem functioning: a consensus of current knowledge. Ecol Monogr. 2005;75:3-35.

50. Maynard DS, Crowther TW, Bradford MA. Fungal interactions reduce carbon use efficiency. Ecol Lett. 2017;20:1034-42.

51. Crowther TW, Thomas SM, Maynard DS, Baldrian P, Covey K, Frey SD, et al. Biotic interactions mediate soil microbial feedbacks to climate change. Proc Natl Acad Sci USA. 2015;112:7033-8.

52. Nelson DW, Sommers LE. Total carbon, organic carbon, and organic matter. In: Sparks DL, Page ALH, editors. Methods of soil analysis part 3-chemical methods. Madison: America Society of Agronomy, Inc; 1996. p. 961-1010.

53. Bremner JM, Mulvaney. Nitrogen-total. In: Sparks DL, Page AL, editors. Methods of soil analysis part 3-chemical methods. Madison: America Society of Agronomy, Inc.; 1996. p. 1085-1121.

54. Sparks DL, Page AL, Helmke PA, Loeppert RH, Mulvaney RL. Nitrogen-inorganic forms. In: Black CA, editor. Methods of soil analysis part 2-agronomy 9. Madison: America Society of Agronomy, Inc; 1965. p. 1149-224.

55. O'Halloran IP, Cade-Menun BJ. Total and organic phosphorus. In: Carter MR, Gregorich EG, editors. editors Soil sampling and methods of analysis (2nd ed) part III-soil chemical analyses. Boca Raton: CRC Press; 2007. p. 267-71.

56. Olsen SR, Cole C, Watanabe FS, Dean L. Estimation of available phosphorus in soils by extraction with sodium bicarbonate. Circular (No. 939). Washington DC: USDA Press; 1954. p. 1-19.

57. Kanehiro Y, Sherman GD. Fusion with sodium carbonate for total elemental analysis. In: Black CA, editor. Methods of soil analysis, part 2-agronomy 9. Madison: America Society of Agronomy, Inc; 1965. p. 952-8.

58. Hendershot $\mathrm{WH}$, Lalande $\mathrm{H}$, Duquette $\mathrm{M}$. Ion exchange and exchangeable cations. In: Carter MR, Gregorich EG, editors. editors Soil sampling and methods of analysis ( $2^{\text {nd }}$ ed) part III- soil chemical analyses. Boca Raton: CRC Press; 2007. p. 203-6.

59. Jury WA, Gardner WR, Gardner WH. Water characteristic function. In: Jury WA, Gardner WR, Gardner WH, editors. Soil physics (5th ed) part 2-water retention in soil. New York: John Wiley \& Sons, Inc.; 1991. p. 61-7.

60. da Silva AP, Kay BD, Perfect E. Characterization of the least limiting water range of soils. Soil Sci Soc Am J. 1994;58:1775-81.

61. Frostegård Å, Bååth $E$, Tunlio A. Shifts in the structure of soil microbial communities in limed forests as revealed by phospholipid fatty acid analysis. Soil Biol Biochem. 1993;25:723-30.

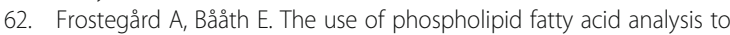
estimate bacterial and fungal biomass in soil. Biol Fertil Soils. 1996;22:59-65.

63. Zelles L. Fatty acid patterns of phospholipids and lipopolysaccharides in the characterisation of microbial communities in soil: a review. Biol Fert Soils. 1999:29:111-29.

64. Mentzer JL, Goodman RM, Balsar TC. Microbial response over time to hydrologic and fertilizations treatments in a simulated wet prairie. Plant Soil. 2006;284:85-100.

65. Lee CK, Barbier BA, Bottos EM, Mcdonald IR, Cary SC. The Inter-Valley Soil Comparative Survey: the ecology of Dry Valley edaphic microbial communities. ISME J. 2012:6(5):1046-57.

66. Bazzicalupo AL, Bálint M, Schmitt I. Comparison of ITS1 and ITS2 rDNA in 454 sequencing of hyper diverse fungal communities. Fungal Ecol. 2013;6:102-9.

67. Caporaso JG, Kuczynski J, Stombaugh J, Bittinger K, Bushman FD, Costello EK, et al. QIIME allows analysis of high-throughput community sequencing data. Nat Methods. 2010:7:335-6.

68. Edgar RC, Haas BJ, Clemente JC, Christopher Q, Rob K. UCHIME improves sensitivity and speed of chimera detection. Bioinformatics. 2011;27:2194-200.

69. Zhang Y, Sun Y. HMM-FRAME: accurate protein domain classification for metagenomic sequences containing frameshift errors. BMC Bioinformatics. 2011;12:198.

70. Li W, Godzik A. Cd-hit: a fast program for clustering and comparing large sets of protein or nucleotide sequences. Bioinformatics. 2006;22:1658-9.

71. Quast C, Pruesse E, Yilmaz P, Gerken J, Schweer T, Yarza P, et al. The SILVA ribosomal RNA gene database project: improved data processing and webbased tools. Nucleic Acids Res. 2013:41:D590-6.

72. Köljalg U, Nilsson RH, Abarenkov K, Tedersoo L, Taylor AFS, Bahram M, et al. Towards a unified paradigm for sequence-based identification of fungi. Mol Ecol. 2013;22:5271-7.

73. Dunford EA, Neufeld JD. DNA stable-isotope probing (DNA-SIP). JoVE. 2010;(42):2027. 
74. Chen Y, Murrell JC. When metagenomics meets stable-isotope probing: progress and perspectives. Trends Microbiol. 2010;18:157-63.

75. Zak JC, Willig MR, Moorhead DL, Wildman HG. Functional diversity of microbial communities: a quantitative approach. Soil Biol Biochem. 1994;26:1101-8

76. Weber K, Legge R. One-dimensional metric for tracking bacterial community divergence using sole carbon source utilization patterns. J Microbiol Methods. 2009;79:55-61.

77. Chen X, Tang J, Jiang L, Li B, Chen J, Fang C. Evaluating the impacts of incubation procedures on estimated Q10 values of soil respiration. Soil Biol Biochem. 2010;42:2282-8.

78. Armstrong RA, Hilton AC. One-way analysis of variance (anova). In: Armstrong RA, Hilton AC, editors. Statistical analysis in microbiology: statnotes. New York: John Wiley \& Sons, Inc; 2010. p. 33-7.

79. Anderson MJ, Willis TJ. Canonical analysis of principal coordinates: a useful method of constrained ordination for ecology. Ecology. 2003;84:511-25.

80. Oksanen J, Blanchet FG, Kindt R, Legendre P, Minchin PR, O'Hara RB, et al. Vegan: community ecology package; 2013. http://cran.r-project.org/ package =vegan

81. Faust K, Sathirapongsasuti JF, Izard J, Segata N, Gevers D, Raes J, et al. Microbial co-occurrence relationships in the human microbiome. PLoS Comput Biol. 2012;8:e1002606

82. Brown MB. 400: a method for combining non-independent, one-sided tests of significance. Biometrics. 1975;31:987-92.

83. Benjamini Y, Hochberg Y. Controlling the false discovery rate: a practical and powerful approach to multiple testing. J Royal Stat Soc. 1995;57:289-300.

84. Bastian M, Heymann S, Jacomy M. Gephi: an open source software for exploring and manipulating networks. San Jose: International AAAI Conference on Weblogs and Social Media; 2009.

85. Bader GD, Hogue CW. An automated method for finding molecular complexes in large protein interaction networks. BMC Bioinformatics. 2003;4(2).

86. Guimera R, Amaral LAN. Functional cartography of complex metabolic networks. Nature. 2005:433:895-900.

87. Olesen JM, Jordi B, Dupont YL, Pedro J. The modularity of pollination networks. Proc Natl Acad Sci USA. 2007:104:19891-6.

88. de Menezes AB, Prendergastmiller MT, Richardson AE, Toscas P, Farrell M, Macdonald LM, et al. Network analysis reveals that bacteria and fungi form modules that correlate independently with soil parameters. Environ Microbiol. 2014;17:2677-89.

89. Alter O, Brown P, Botstein D. Singular value decomposition for genomewide expression data processing and modeling. Proc Natl Acad Sci USA. 2000:97:10101-6

90. Langfelder $\mathrm{P}$, Horvath $\mathrm{S}$. Eigengene networks for studying the relationships between co-expression modules. BMC Syst Biol. 2007;1:54.

91. Breiman L. Random forests. Mach Learn. 2001;45:5-32.

92. Cutler DR, Edwards TC, Beard KH, Cutler A, Hess KT, Gibson J, Lawler JJ. Random forests for classification in ecology. Ecology. 2007;88:2783-92.

93. Liaw A, Wiener M. Classification and regression by randomForest. R News. 2002;2:17-22.

94. Fortmannroe S. A3: Accurate, adaptable, and accessible error metrics for predictive models. R package version 1.0.0. 2015. https://CRAN.R-project.org/ package $=A 3$.

95. Archer E. rfPermute: estimate permutation $p$-values for random forest importance metrics. R package version 2.1.1. 2016. https://CRAN.R-project. org/package=rfPermute.

96. Delgado-Baquerizo M, Maestre FT, Reich PB, Jeffries TC, Gaitan JJ, Encinar D, et al. Microbial diversity drives multifunctionality in terrestrial ecosystems. Nat Commun. 2016;7:10541.

97. Byrne BM. Structural equation modeling with AMOS: basic concepts, applications and programming. (2nd ed). New York, NY, USA: Routledge; 2010.

\section{Ready to submit your research? Choose BMC and benefit from:}

- fast, convenient online submission

- thorough peer review by experienced researchers in your field

- rapid publication on acceptance

- support for research data, including large and complex data types

- gold Open Access which fosters wider collaboration and increased citations

- maximum visibility for your research: over $100 \mathrm{M}$ website views per year

At BMC, research is always in progress.

Learn more biomedcentral.com/submissions 